\title{
In vivo mucoadhesive strength appraisal of gum Manilkara zapota
}

\author{
Singh Sudarshan ${ }^{1, *}$, Bothara Sunil B ${ }^{2}$ \\ ${ }^{1}$ H.S.B.P.V.T., GOI, College of Pharmacy, Kashti, Maharashtra, India, ${ }^{2}$ Bhagwan college of Pharmacy, Aurangabad, \\ Maharashtra India
}

\begin{abstract}
The mucilage (MMZ) extracted from the seeds of Manilkara zapota (Linn.) P. Royen syn. using maceration techniques was evaluated for mucoadhesive strength by various in vitro and in vivo methods. The result showed that mucoadhesive strength of seeds mucilage have comparable property toward natural and synthetic polymers such as Guar Gum and hydroxyl propyl methyl cellulose (HPMC E5LV) under the experimental conditions used in this study. Briefly, it could be concluded that the seed mucilage of Manilkara zapota can be used as a pharmaceutical excipient in oral mucoadhesive drug delivery systems. Further, it may be appropriate to study the changes in these properties after chemical modifications.
\end{abstract}

Uniterms: Manilkara zapota/use/pharmaceutics. Manilkara zapota/evaluation/mucoadhesive strength. Drugs/mucoadhesives/oral delivery systems. Natural polymers. Pharmaceutical excipients.

Mucilagem (MMZ) extraída das sementes de Manilkara zapota (Linn.) P. Royen syn utilizando técnicas de maceração foi avaliada por sua força mucoadesiva por vários métodos in vitro e in vivo. O resultado mostrou que a força mucoadesiva das sementes mucilaginosas tem propriedade comparável aos polímeros naturais e sintéticos, tais como goma Guar e hidroxipropilmetil celulose (HPMC E5LV) nas condições experimentais utilizadas neste estudo. Brevemente, se pode concluir que a mucilagem de semente de Manilkara zapota pode ser usada como um excipiente farmacêutico em sistemas de liberação de fármacos mucoadesivos por via oral. Pode ser apropriado o estudo posterior de mudanças nessas propriedades após modificações químicas.

Unitermos: Manilkara zapota/uso/farmacotécnica. Manilkara zapota/avaliação/força mucoadesiva. Fármacos/mucoadesivos/sistemas de liberação por via oral. Polímeros naturais. Excipientes farmacêuticos.

\section{INTRODUCTION}

Mucilages are naturally occurring, high-molecularweight (approximately 200,000), polyuronides consisting of sugar and uronic acid units (Trease, Evans, 2002). These are esters of sulphuric acid, wherein ester group is a polysaccharide complex (Kokate, Purohit, Gokhale, 2005). Chemically, mucilages resemble gums and pectins but differ in their physical properties. Gums swell in water to form sticky, colloidal dispersions and pectins gelatinize in water, while mucilages form slippery, aqueous colloidal dispersions (Bhardwaj et al., 2000; Jani, Shah, 2008). Gums are considered to be pathological products formed upon injury of the plant or owing to unfavorable conditions such as drought, by a breakdown of cell walls

\footnotetext{
*Correspondence: Dr. Sudarshan Singh. H.S.B.P.V.T'S. Group of Institutions, College of Pharmacy. Kashti, Ahmednagar - 414701 - Maharashtra, India. E-mail: sudarshansingh83@hotmail.com
}

(extracellular). On the other hand mucilage is regarded as normal physiological product of metabolism formed within the cell or deposited on it in layers. Mucilage in plants is thought to aid in water storage and seed germination, and to act as a membrane thickener and food reserve. Among the richest sources of mucilage are cacti (and other succulents), and flax seeds.

Bioadhesive systems applied to mucous membrane are frequently defined as mucoadhesive, but the terms are interchangeable (Leung, Robinson, 1990). It is feasible to design a bio (muco) adhesive system in different dosage forms, since the properties of adhesion largely depend on the features of the material used in its preparation. Therefore, several conventional drug delivery systems already in use can become bioadhesive after redesign by including bioadhesive substances in their formulation. This approach to confer bioadhesion properties has been widely applied in the development of a number of drug delivery systems (Asana, 2007). 
Since the seeds are rich source of mucilage and such mucilages can prove to be better alternative to presently available mucoadhesive agents, this study was undertaken.

Present study describes characterization of mucilage isolated from the seeds of Manilkara zapota as a mucoadhesive agent after evaluating it by various reported methods such as shear stress measurement, Wihelmy's method, detachment force measurement, recording of adherence, falling sphere method, rotating cylinder method, falling liquid film technique, ex-vivo residence time, in-vitro wash off test, and in vivo mucoadhesive strength.

\section{MATERIAL AND METHODS}

\section{Material}

Fruits of Manilkara zapota were collected from the forest of Rajgamar, District Korba, Chhattisgarh in the month of April-June and authenticated by Prof. H. B. Singh, NISCAIR, New Delhi, India. De-ionized water was used for all experiments. All other chemicals used were of analytical reagent grade.

\section{Methods}

\section{Isolation of Mucilage from seeds of M. zapota}

$100 \mathrm{~g} / \mathrm{kg}$ powdered seeds were soaked in distilled water at room temperature for 24 hours. The resultant slurry was heated at temperature $100{ }^{\circ} \mathrm{C}$ for $1 \mathrm{~h}$, allowed to cool for $1 \mathrm{~h}$ and was filtered through the muslin cloth. The filtrate was centrifuged (Remi) at $3000 \mathrm{rpm}$ for 10 minutes. Acetone was added to the filtrate to precipitate the mucilage. The precipitate was filtered and then washed with chloroform. The mucilage was then dried at $40{ }^{\circ} \mathrm{C}$ in hot-air oven (Bio-Tech) and then passed through mesh $\# 120$ and stored in desiccators until used for further studies (Kulkarni et al., 2002)

\section{Mucoadhesive strength assessment}

The mucoadhesive characterization of synthetic, semi synthetic or natural gum involves various evaluation methods. In order to confirm mucoadhesive character of the mucilage, the study was performed in triplicate along with other existing known mucoadhesive polymers such as hydroxyl propyl methyl cellulose E5LV (HPMC E5LV) and Guar gum (GG) (Pranshu, Madhav, 2011) to compare the strength of adhesion of test and standard agents.

\section{Measurement of adhesive strength by shear stress measurement}

shear stress measure the force that cause a muco- adhesive to slide with respect to the mucus layer in direction parallel to their place of contact of adhesion. The test was performed at various concentrations of mucoadhesive solution such as $1 \%, 2 \%, 3 \% \mathrm{w} / \mathrm{v}$ for standard and test material (GG, HPMC E5LV and MMZ). A specified amount of prepared solution was spread on three sets of glass slides. Another clean glass slide was placed over the first plate and applied $100 \mathrm{~g}$ weight rolling on the glass plates to spread the polymer solution uniformly. It was kept aside for 15, 30 and $60 \mathrm{~min}$ respectively for different sets. The lower glass plate was fixed in a hook and the upper was connected to the end pan through the pulley. Each set was subjected to the test after the stipulated time i.e. 15, 30 and 60 min respectively and weight was placed in pan with an increasing manner until the plates are detached off. The weight required to detach plate was noted (Peh, Wong, 1999).

\section{Measurement of adhesive strength by Wihelmy's method}

Wihelmy's method measures equilibrium surface or interfacial tension at an air-liquid or liquid-liquid interface (Figure 1). A small glass plate $(2 \times 5 \mathrm{~cm})$ was coated by dipping into a $1 \% \mathrm{w} / \mathrm{v}$ solution of standard and test mucoadhesive agent. The mucin was collected from goat intestine and kept in a suitable container and the temperature was maintained at $37^{\circ} \mathrm{C}$. Nylon thread was attached at one end of the glass plate. It was allowed undisturbed for 5, 10, 15 and $30 \mathrm{~min}$. Provision was given to raise the weight from the other end. At specified intervals, weight was added to detach the coated glass plate from mucin and the force required to pull the plate out of the gel was determined under experimental condition. Six plates were tested for each material and the average weights required was calculated (Rao et al., 1998).

\section{Measurement of adhesive strength by detachment force Measurement}

Mucoadhesive strength was measured using detachment force method in which goat intestine was collected from slaughter house and transferred to kreb solution. During this experiment the intestine was placed on one glass slide and tied on both side of the assembly (Figure 2). The glass slide with the intestine was fixed on one side floor below the modified physical balance. The tablets of $125 \mathrm{mg}$ each bearing formulation codes F1 to F7 were prepared as described in Table I wherein ratio of 1:1 with barium sulphate (Microbar HD) and mucoadhesive agent (MMZ, GG, HPMC E5LV and Lactose as control) by addition of $5 \% \mathrm{w} / \mathrm{v}$ polyvinlypyrrolidon binding agent solution to make dough mass. This was passed through sieve 


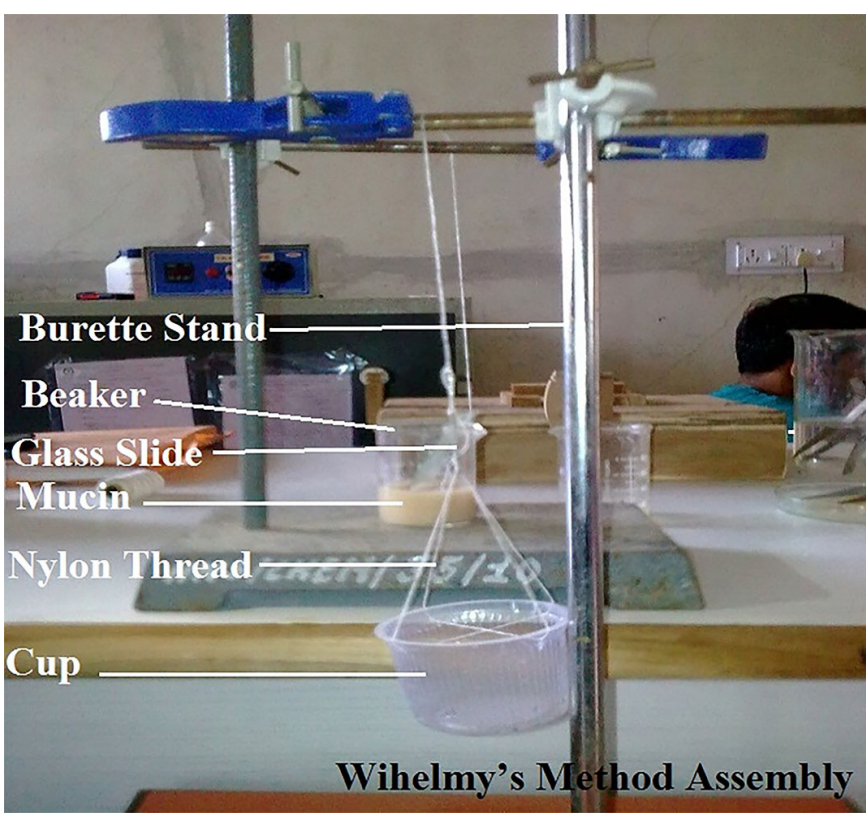

FIGURE 1 - Wihelmy's Method to measure mucoadhesive strength.

no. 10 to obtain granules. After drying these were passed through the sieve no. 18 to remove fines. Tablets of $6 \mathrm{~mm}$ were prepared on eight-station compression (Clit Jemkay Engineering) machine. Formulation F4 to F7 was pasted on another glass slide and balanced on the assembled physical balance with a beaker on other side which was used to hold the water, amount of water in grams which require to detach the tablet were recorded (Nafee et al., 2003).

\section{Measurement of adhesive strength by recording of adherence}

the tablets prepared as per above procedure were placed on the slide with goat intestinal segment and lightly pressed with forcep, the assembly kept in undisturbed condition for a fixed time interval 5, 10, 15 and $30 \mathrm{~min}$ than water was added slowly in drop wise manner to the

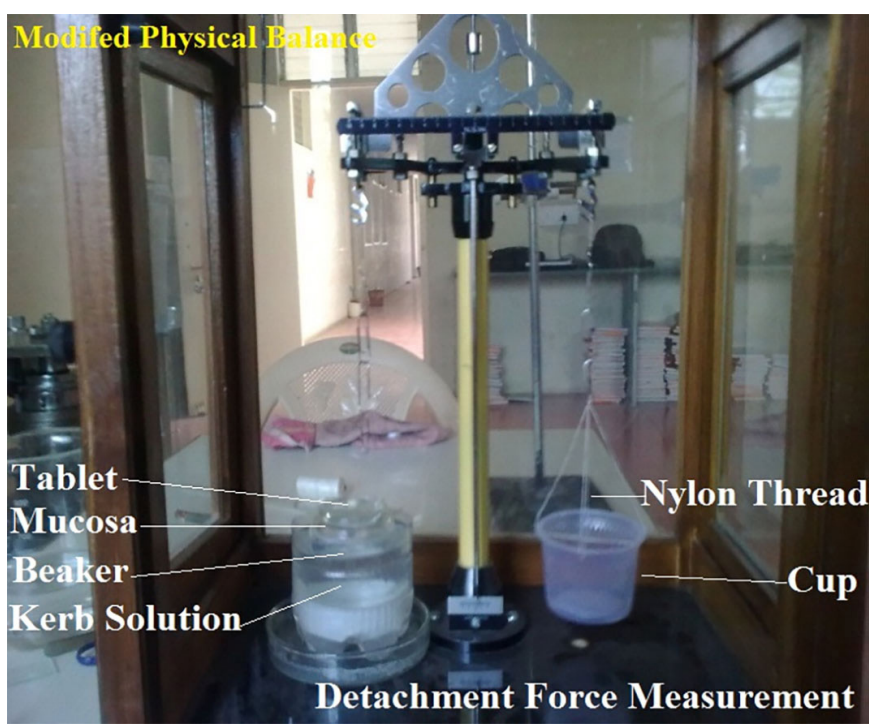

FIGURE 2 - Mucoadhesive strength measurement by detachment force measurement.

cup. The amount of water in gm required to pull out the tablet from intestinal segment represent the force required to pull the tablet against the adhesion (Shinde et al., 2010). The above procedure was performed in triplicate and the force in Newton's was calculated by Equation 1:

$$
\mathrm{F}=\frac{0.00981 \mathrm{~W}}{2}
$$

whereas, $\mathrm{W}$ is the amount of water.

\section{Measurement of adhesive strength by falling sphere method}

falling sphere method was used for characterizing mucoadhesive strength. Mucus was taken out by pressing out the intestine by forcep and filled in a clean burette. Mustard grains coated with test material (MMZ) and standard (Guar Gum and HPMC E5LV) was taken and slowly placed at the top of the mucus layer. Time taken by

TABLE I - Formulation code for the X-ray and physical characterization of mucilage tablet

\begin{tabular}{lccccccc}
\hline Ingredients (in mg) & F1 & F2 & F3 & F4 & F5 & F6 & F7 \\
\hline MMZ & 50 & - & - & - & 100 & - & - \\
GG & - & 50 & - & - & - & 100 & - \\
HPMC & - & - & 50 & - & - & - & 100 \\
PVP (w/v) $_{\text {BaSO }_{4}}^{\text {Lactose }}$ & qs & qs & qs & qs & qs & qs & qs \\
Aerosil & 50 & 50 & 50 & 50 & - & - & - \\
\hline
\end{tabular}

MMZ: Mucilage of Manilkara zapota, GG: Guar Gum, HPMC: Hydroxyl propyl methyl cellulose E5LV, PVP: Polyvinylpyrrolidone 
the grains to cover 50 divisions in the burette was noted (Rao, Buri, 1989).

\section{Measurement of adhesive strength by falling liquid film technique}

the intestine of goat was separated and cut longitudinally. This separated portion was placed on the semi cylindrical plexiglass support, and washed with saline solution for $30 \mathrm{~min}$ at rate of $30 \mathrm{~mL} / \mathrm{min}$. Then 25 $\left(\mathrm{N}_{\mathrm{o}}\right)$ counted granule of mucilage (prepared by adding water) were hydrated with little amount of water and were dispersed on the mucosal tissue and left for $20 \mathrm{~min}$ for interaction with mucosal surface during this period whole assembly was placed in a constant humidity chamber. At the end, the system was washed with phosphate buffer $\mathrm{pH}$ 7.2 for $20 \mathrm{~min}$ at the rate of $22 \mathrm{~mL} / \mathrm{min}$ and the number of granules of mucilage remaining on the mucosal surface (Ns) was counted. The adhesive strength was determined using the Equation 2 given below (Smart, Kellaway, Worthington, 1984).

$$
\text { Percentage adhesive strength }=\frac{\mathrm{N}_{\mathrm{S}}}{\mathrm{N}_{0}}
$$

\section{Measurement of adhesive strength by rotating cylinder method}

mucoadhesive strength was determined by rotating cylinder method in which tablets of standard and test material (125 mg) was compressed using $6.0 \mathrm{~mm}$ punch using a rotary compression machine, by keeping constant compression pressure for each polymer. Each tablet was placed on freshly excised goat intestine and hydrated with few drops of distilled water. The whole system containing tablet and intestine was then placed on the stainless steel basket of USP type I apparatus with the aid of thread and the basket was immersed in the dissolution jar filled with phosphate buffer $\mathrm{pH} 7.2$ at $37^{\circ} \mathrm{C}$. It was rotated at 125 $\mathrm{rpm}$. The time required for the detachment, disintegration or erosion of tablet was recorded (Vjera, Davide, Andreas, 2005).

Measurement of adhesive strength by ex vivo residence time

The residence time for mucilage tablet was measured using modified USP dissolution test apparatus. The test and standard mucilage tablets $(125 \mathrm{mg})$ were pressed over excised goat mucosa for $30 \mathrm{~s}$ after previously being secured on glass slab and was immersed in a jar of dissolution apparatus containing $750 \mathrm{~mL}$ of phosphate buffer, pH 6.2 at $37^{\circ} \mathrm{C}$. The paddle type II apparatus of the USP dissolution apparatus as adjusted at a distance of $5 \mathrm{~cm}$ up from the tablet and rotated at $25 \mathrm{rpm}$. The time for complete erosion or detachment from the mucosa was recorded (Bhavin et al., 2009).

\section{Measurement of adhesive strength by in vitro wash off test}

mucoadhesive strength study was conducted on modified disintegration test (DT) assembly. The cylindrical part of disintegration apparatus was replaced with a glass slide $\left(10 \times 2 \mathrm{~cm}^{2}\right)$ attached with a stainless steel stick. The tissue of intestine $\left(1 \times 1 \mathrm{~cm}^{2}\right)$ was fixed on slide with thread in such a way that the mucosal part will be outside. The tablet was fixed on mucosal part of tissue with little pressure. The modified assembly was dipped down in $500 \mathrm{~mL}$ of $0.1 \mathrm{~N} \mathrm{HCl}$ and the motor of DT apparatus was switched on. The time of detaching the tablet from the tissue surface was considered as wash off time for that tablet (Agaiah, Swamy, Praveen, 2011).

\section{Statistical analysis}

Results obtained for above mucoadhesive strength assessment are expressed as mean \pm Standard Error Mean (SEM) and subjected to one-way analysis of variance (ANOVA) followed by Dunnett's test considering Guar Gum and HPMC E5LV as standard and values with $P<$ 0.05 were considered to be statistically significant.

\section{In vivo bioadhesive study}

\section{Preparation of barium sulphate tablet}

The in vivo residence time of tablets was measured on white New Zeeland Rabbit. The protocol for animal studies was approved by Institutional Animal ethical committee (IEAC/HNSIPER/RJK/07/2010). The standard and test mucoadhesive agent $(125 \mathrm{mg})$ tablets were prepared in ratio of 1:1 with barium sulphate (Microbar HD) and mucoadhesive agent (MMZ, GG, HPMC E5LV and Lactose as control) as presented in Table I.

Barium sulphate loaded tablets were used to study the bioadhesive character and the mean residence time of mucoadhesive agent in the intestine. Six healthy white New Zeeland rabbits weighing about $2.5 \mathrm{~kg}$ were selected separately for test and control mucoadhesive agent. Tablets were administered orally using modified oral feeding tube in each rabbit (Senthil et al., 2010). X-ray photographs were taken at specified time intervals $(0,4$ and $8 \mathrm{hr})$ with the help of X-ray Machine (GE ELPRO, Power supply was $73 \mathrm{KVP}, 120 \mathrm{mAs}$ for two second) and then residence time was measured from the photographs. 


\section{RESULTS}

\section{Measurement of adhesive strength by shear stress analysis}

The result (Table II) of shear stress measurement indicated that the mucoadhesive strength possessed by test material isolated (MMZ) from seeds and standard (HPMC E5LV and Guar Gum) are in order of GG $>$ MMZ> HPMC E5LV respectively. The initial measurement values for shear stress, (time $15 \mathrm{~min}$ ) normalized and the values at 30 and 60 min reported as increase in ratio when compared with time. The mucoadhesive strength of MMZ was significantly higher than HPMC E5LV, however the strength was significantly lower than standard i.e. Guar Gum.

\section{Measurement of adhesive strength by Wihelmy's, detachment force and recording adherence method}

The result of Wihelmy's method showed that the force of adhesion in Newton required to detach $1 \% \mathrm{w} / \mathrm{v}$ coated plate from the mucus gel after 30 min was 0.1966 $\mathrm{N}$ for MMZ however standard polymer HPMC E5LV showed poor adhesive character with $0.1176 \mathrm{~N}$ to detach the plate, in comparison with test material towards the mucus gel (Figure 3). The mucoadhesive strength of MMZ was significantly higher than HPMC E5LV, however the strength was significantly lower than standard i.e. Guar Gum.

Detachment force measurement analysis showed that the force of adhesion in Newton required to detach

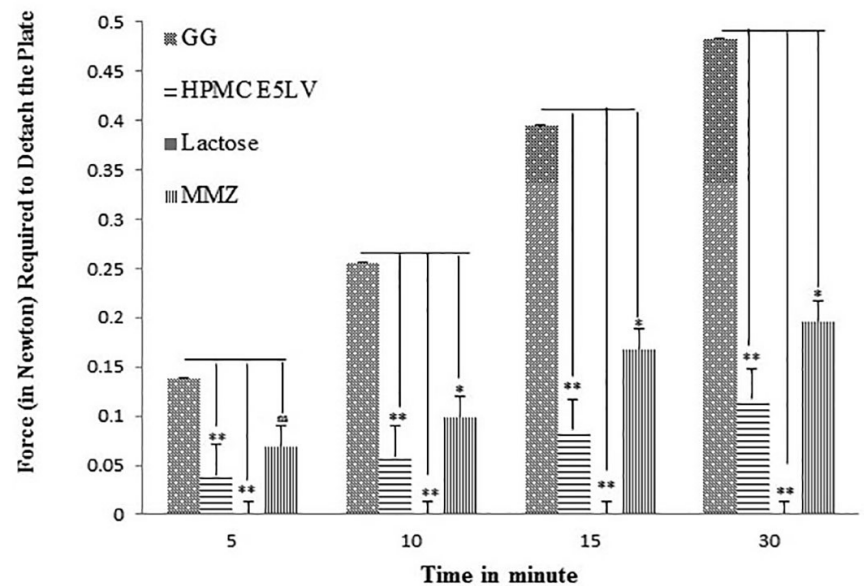

FIGURE 3 - Compression between Mucoadhesive Strength of Guar Gum and HPMC E5LV: Hydroxyl Propyl Methyl Cellulose E5LV (Standard) and MMZ: mucilage of Manilkara zapota (Test Materials) and Lactose (Control). Values are expressed as mean $\pm \operatorname{SEM}(n=6)$. Data was analyzed by one way ANOVA followed by Dunnett test (Compared with standard Guar Gum), ${ }^{(\text {ns) }} \mathrm{p}>0.05 ;{ }^{*} \mathrm{p}<0.05 ; * * \mathrm{p}<0.01 ; * * \mathrm{p}<0.001$.

mucilage tablet from the intestine after $30 \mathrm{~min}$ was $0.0318 \mathrm{~N}$ for MMZ, however standard polymer HPMC E5LV showed poor adhesive character with $0.0049 \mathrm{~N}$ to detach the plate, in comparison with test material (Figure 4). The mucoadhesive strength of MMZ was significantly higher than HPMC E5LV, however the strength was significantly lower than standard i.e. Guar Gum.

Mucoadhesive strength evaluated using recording of adherence analysis showed that the force of adhesion in Newton required to detach mucilage tablet from the

TABLE II - Shear stress (in Newton) measurement of standard (Guar Gum and HPMC E5LV) and test material (Mucilage)

\begin{tabular}{lcccc}
\hline \multirow{2}{*}{$\begin{array}{l}\text { Polymer } \\
\text { Concentration } \\
(\%) \mathrm{w} / \mathrm{v}\end{array}$} & \multicolumn{2}{c}{ Weight in gm required to detach glass plate at different time interval } \\
\cline { 3 - 5 } GG & 1 & $0.154 \pm 0.0367$ & $0.172 \pm 0.0031$ & 60 minute \\
\hline & 2 & $0.161 \pm 0.0016$ & $0.183 \pm 0.0006$ & $0.198 \pm 0.0015$ \\
& 3 & $0.166 \pm 0.0036$ & $0.190 \pm 0.0037$ & $0.219 \pm 0.0025$ \\
\hline \multirow{2}{*}{ HPMC E5LV } & 1 & $0.059 \pm 0.0028^{*}$ & $0.064 \pm 0.0037^{* *}$ & $0.078 \pm 0.0040^{* *}$ \\
& 2 & $0.071 \pm 0.0020^{* *}$ & $0.079 \pm 0.0027^{* *}$ & $0.086 \pm 0.0022^{* *}$ \\
& 3 & $0.091 \pm 0.00081^{* *}$ & $0.098 \pm 0.0005^{* *}$ & $0.098 \pm 0.0008^{* *}$ \\
\hline \multirow{2}{*}{ MMZ } & 1 & $0.122 \pm 0.0326 \mathrm{~ns}$ & $0.129 \pm 0.0018^{* *}$ & $0.135 \pm 0.0025^{* *}$ \\
& 2 & $0.129 \pm 0.0005^{* *}$ & $0.133 \pm 0.0024^{* *}$ & $0.138 \pm 0.0002^{* *}$ \\
\hline
\end{tabular}

MMZ: Mucilage of Manilkara zapota, GG: Guar Gum, HPMC: Hydroxyl propyl methyl cellulose E5LV. Values are expressed as mean $\pm \operatorname{SEM}(\mathrm{n}=6)$. Data was analyzed by one way ANOVA followed by Dunnett test (Compared with standard Guar Gum), ${ }^{(n s)} \mathrm{p}>0.05 ; * \mathrm{p}<0.05 ; * * \mathrm{p}<0.01 ; * * * \mathrm{p}<0.001$ 


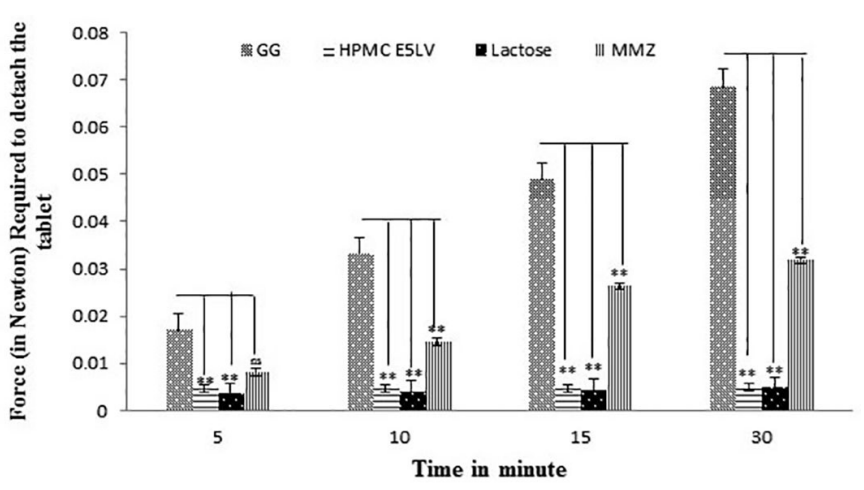

FIGURE 4 - Compression between mucoadhesive strength of Guar Gum and HPMC E5LV (Standard) and MMZ (Test Materials) and Lactose (Control). Values are expressed as mean \pm SEM $(n=6)$. Data was analyzed by one way ANOVA followed by Dunnett test (Compared with standard Guar Gum), ${ }^{(\mathrm{ns})} \mathrm{p}>0.05$; $*_{\mathrm{p}}<0.05 ; * * \mathrm{p}<0.01 ; * * * \mathrm{p}<0.001$.

intestine after $30 \mathrm{~min}$ was $0.714 \mathrm{~N}$ for $\mathrm{MMZ}$, however standard polymer HPMC E5LV showed poor adhesive character with $0.0229 \mathrm{~N}$ to detach the plate, in comparison with test material (Figure 5). The mucoadhesive strength of MMZ was significantly higher than HPMC E5LV, however the strength was significantly lower than standard i.e. Guar Gum.

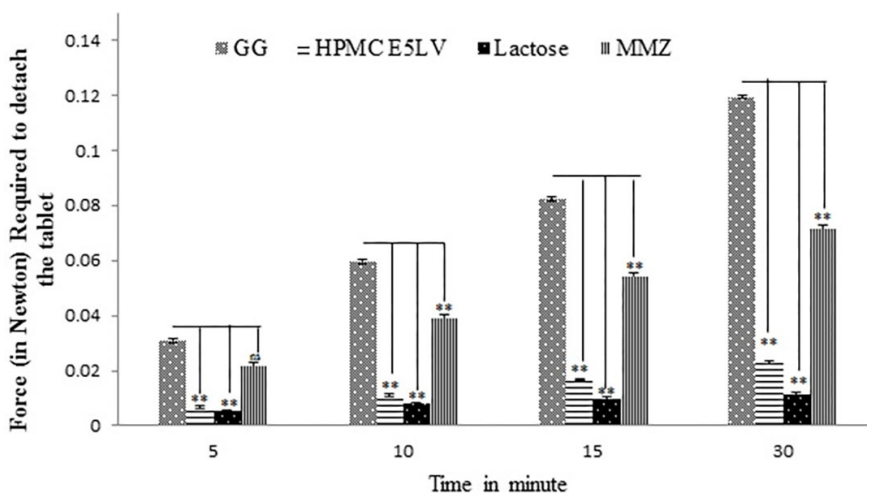

FIGURE 5 - Compression between mucoadhesive strength of Guar Gum and HPMC E5LV (Standard) and MMZ (Test Materials) and Lactose (Control). Values are expressed as mean $\pm \operatorname{SEM}(\mathrm{n}=6)$. Data was analyzed by one way ANOVA followed by Dunnett test (Compared with standard Guar Gum), ${ }^{(n s)} p>0.05$; ${ }^{*} \mathrm{p}<0.05 ; * \mathrm{*}<0.01 ; * * * \mathrm{p}<0.001$.

\section{Measurement of adhesive strength by falling sphere analysis}

The result of falling sphere analysis showed that (Figure 6) time required to cover division of burette by polymer-coated grain is higher for Guar Gum coated grain and lowest for HPMC E5LV coated grain. The result showed that mucoadhesive strength of $\mathrm{MMZ}$ was significantly higher than HPMC E5LV, however the strength is significantly lower than standard i.e. Guar Gum.

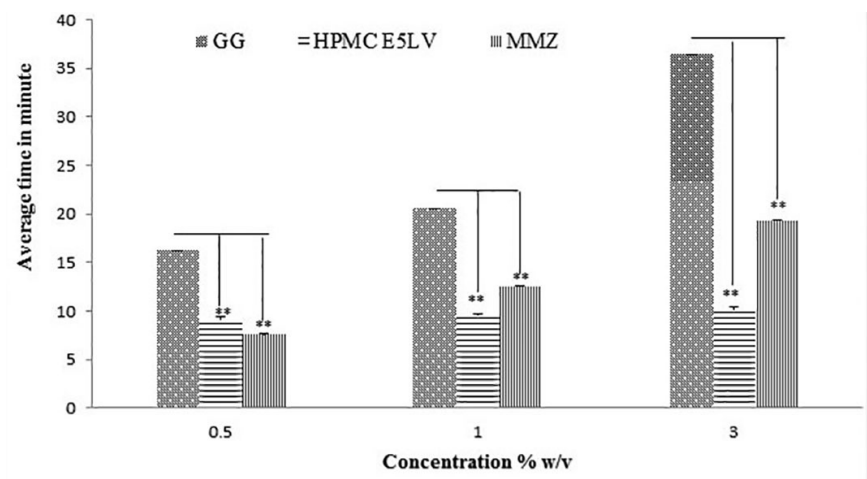

FIGURE 6 - Time taken by polymer coated grain to cover the given distance during falling sphere analysis. Values are expressed as mean $\pm \operatorname{SEM}(n=6)$. Data was analyzed by one way ANOVA followed by Dunnett test (Compared with standard Guar Gum), ${ }^{(n s)} \mathrm{p}>0.05 ;{ }^{*} \mathrm{p}<0.05 ;{ }^{* *} \mathrm{p}<0.01 ;{ }^{* * *} \mathrm{p}<0.001$.

\section{Measurement of adhesive strength by Falling liquid analysis}

The result indicated that the adhesive strength was higher for formulation F6 (88.0 min) which comprises of Guar Gum and lowest for formulation no F4 (08.0 mint) which comprises of lactose. The result of percentage adhesive strength was obtained in following order GG> MMZ> HPMC E5LV> Lactose. The mucoadhesive strength of F5 (72.0 min), was significantly higher than F4 and F7 (60.0 min), however the strength is significantly lower than standard i.e. F6.

\section{Measurement of adhesive strength by rotating cylinder analysis}

The result of rotating cylinder analysis is presented in Table III. The observation revealed that detachment time and erosion time is higher for formulation no F6 which comprises of Guar Gum and lowest for formulation no F4 which comprises of lactose. The order of detachment and erosion time was obtained in following order $\mathrm{GG}>\mathrm{MMZ}>$ HPMC E5LV $>$ Lactose. The mucoadhesive strength of F5, was significantly higher than F4 and F7, however the strength is significantly lower than standard i.e. F6.

\section{Measurement of adhesive strength by ex vivo residence and in vitro wash off time}

The result of ex vivo residence and in vitro wash off 
TABLE III - Detachment and Erosion time of formulation F4 to F7 during rotating cylinder analysis

\begin{tabular}{lcc}
\hline Polymer tablet & $\begin{array}{c}\text { Detachment } \\
\text { Time }(\mathrm{min})\end{array}$ & $\begin{array}{c}\text { Disintegration or } \\
\text { Erosion Time }(\mathrm{min})\end{array}$ \\
\hline F4 & $001.0 \pm 0.040^{* *}$ & $01.00 \pm 0.081^{* *}$ \\
F5 & $350.0 \pm 0.24^{* *}$ & $095.0 \pm 0.326^{* *}$ \\
F6 & $370.0 \pm 0.367$ & $422.0 \pm 0.163$ \\
F7 & $000.5 \pm 0.285^{* *}$ & $022.0 \pm 0.081^{* *}$ \\
\hline
\end{tabular}

Values are expressed as mean $\pm \operatorname{SEM}(n=6)$

Data was analyzed by one way ANOVA followed by Dunnett test (Compared with standard Guar Gum), ${ }^{(\mathrm{ns})} \mathrm{P}>0.05 ; * \mathrm{p}<0.05$; $* * \mathrm{p}<0.01 ; * * * \mathrm{p}<0.001$

time is tabulated in Table IV. The observation revealed that the polymer tablets of F6 (Guar Gum) have longer ex-vivo residence and in vitro wash off time, and polymer tablet of $\mathrm{F} 4$ have shortest one. The results of ex vivo residence and in vitro wash off time was obtained in following order GG> MMZ > HPMC E5LV > Lactose. The mucoadhesive strength of F5, was significantly higher than F4 and F7, however the strength is significantly lower than standard i.e. F6.

TABLE IV - Mucoadhesive strength evaluation by ex vivo residence and in vitro wash off test for Formulation F4-F7

\begin{tabular}{lcc}
\hline Polymer tablet & $\begin{array}{c}\text { Ex vivo residence } \\
\text { time (minute) }\end{array}$ & $\begin{array}{c}\text { In vitro wash off } \\
\text { time (minute) }\end{array}$ \\
\hline F4 & $101 \pm 0.4205^{* *}$ & $013 \pm 0.4164^{* *}$ \\
F5 & $432 \pm 0.4164^{* *}$ & $083 \pm 0.4327 * *$ \\
F6 & $736 \pm 0.4164$ & $086 \pm 0.4450$ \\
F7 & $276 \pm 0.4450^{* *}$ & $004 \pm 0.4491 * *$ \\
\hline
\end{tabular}

Values are expressed as mean \pm SEM $(n=6)$

Data was analyzed by one way ANOVA followed by Dunnett test (Compared with standard Guar Gum), ${ }^{\text {(ns) }} \mathrm{P}>0.05 ; * \mathrm{P}<0.05$; $* * \mathrm{P}<0.01 ; * * * \mathrm{P}<0.001$

\section{In vivo bioadhesive study}

The result of X-ray analysis is presented in Figure 7-10. The X-ray figures revealed that the tablet containing Guar Gum present in intact form for $8 \mathrm{~h}$ while tablets containing HPMC E5LV and MMZ although present but not in intact form. The lactose containing tablet was disintegrated in stomach itself just after ingestion of tablet.

\section{DISCUSSION}

\section{Mucoadhesive strength of isolated mucilage}

The process of mucoadhesion involving a polymeric

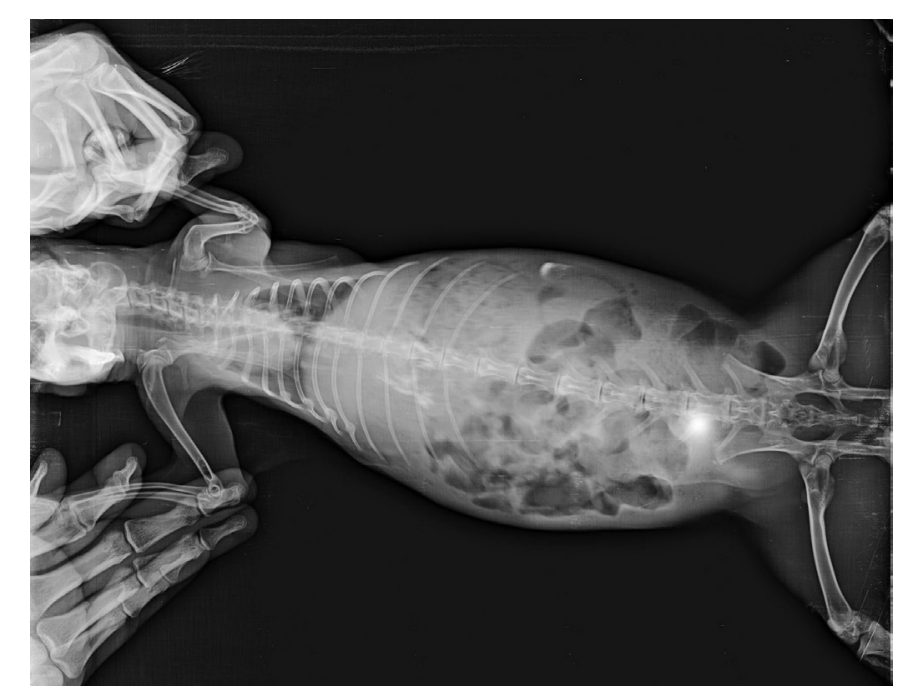

FIGURE 9 - X-ray image of formulation containing HPMC E5LV with barium sulphate after eight hour.

drug delivery platform is a complex one that includes wetting, adsorption and interpenetration of polymer chains amongst various other processes. The success and degree of with barium sulphate after eight hour.

FIGURE 7 - X-ray image of formulation containing MMZ with barium sulphate after eight hour.

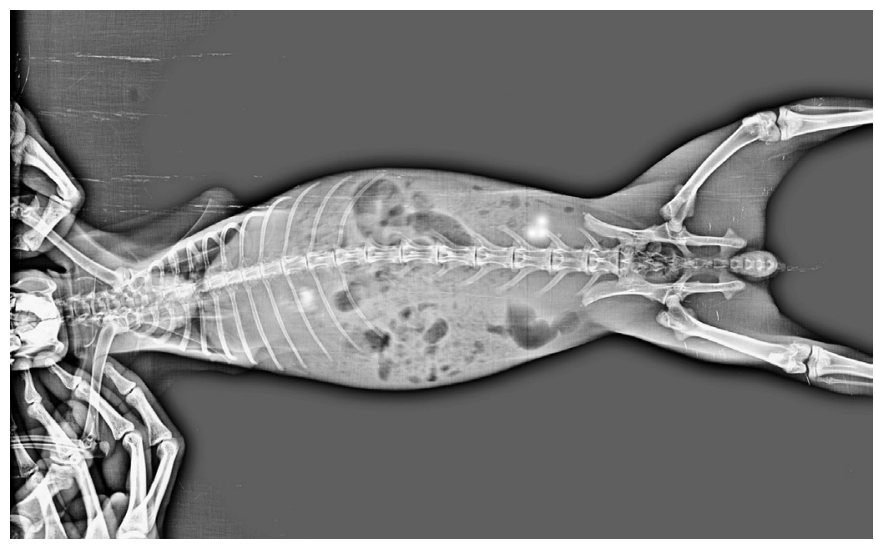

FIGURE 8 - X-ray image of formulation containing Guar Gum 


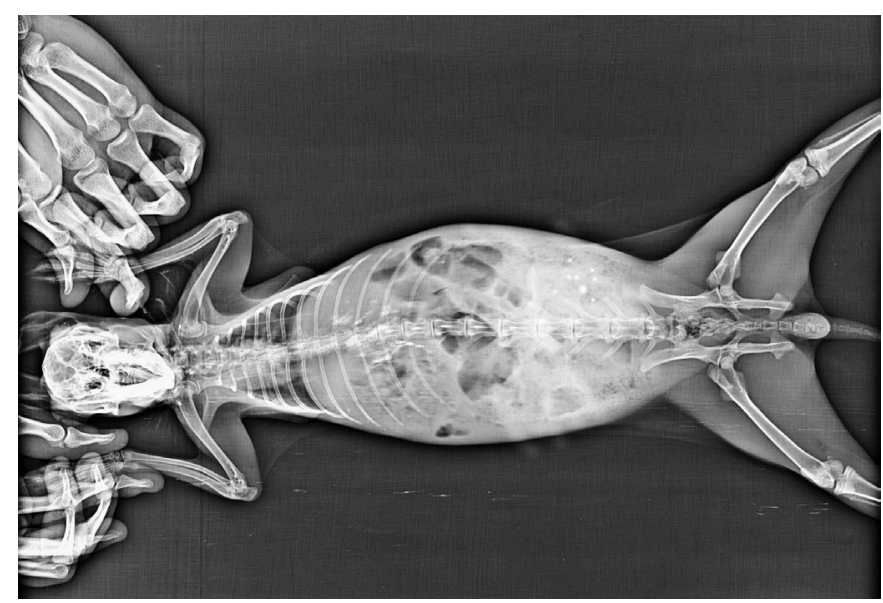

FIGURE 10 - X-ray image of formulation containing lactose with barium sulphate after four hour.

mucoadhesion bonding is influenced by various polymerbased properties such as the degree of cross-linking, chain length and the presence of various functional groups. The attractiveness of mucosal-targeted controlled drug delivery of active pharmaceutical ingredients (APIs), has led formulation scientists to engineer numerous polymeric systems for such tasks. The mucilage of Manilkara zapota was to be characterized for its relative mucoadhesive and related properties. Therefore, standard and widely used gum like HPMC and Guar Gum were used for comparative assessment. Various properties requisite for mucoadhesive dosage like, mucoadhesive strength, adhesiveness and Physiochemical of mucilage were evaluated. So, in order to develop a mucoadhesive excipient there is need of in vitro and in vivo mucoadhesion testing setups.

\section{Mucoadhesive strength measurements by shear stress analysis}

The adhesive strength of test mucoadhesive material determined from shear stress analysis was found to be $0.099 \mathrm{~N}$ for MMZ. The results indicate that adhesive strength of MMZ is more or less equivalent to adhesive strength of Guar Gum but it is better than HPMC E5LV which indicates that test material possess good adhesive strength.

\section{Measurement of adhesive strength by Wihelmy's, detachment force and recording of adherence}

The adhesive strength of test and standard mucoadhesive material determined from Wihelmy's, detachment force and recording of adherence. Result indicated that force of adhesion in Newton for test material was found to be statistically significant than HPMC E5LV.
The control group, were polymer was replaced by Lactose, showed no mucoadhesion. The result of mucoadhesive strength by Wihelmy's, Detachment Force and Recording of Adherence indicated that force (in Newton) required to detach the tablet is gradually increasing for test as well as standard with respect to time except control i.e. Lactose, Which suggested that test material have potential of mucoadhesiveness. Further, the results of adhesive strength for test material from falling sphere analysis, rotating cylinder and falling liquid analysis also confirmed the same.

\section{Measurement of adhesive strength by ex vivo and in vitro wash off mucoadhesive strength}

The ex vivo mucoadhesive strength study showed that the bioadhesion characteristics of test and standard mucoadhesive polymer were affected by type and concentration of polymer. Viscosity of polymer also affects the bioadhesive strength of tablet as reported earlier by Deshmukh, Jadhav, Sakarkar, 2010. The result was further supported by in vitro wash off test for test mucoadhesive agent.

\section{In vivo mucoadhesive strength}

The result of in vivo test, indicated that test material possess strong mucoadhesive property as revealed by $\mathrm{X}$-ray figures at different time intervals. The tablet resists disintegration for longer period (up to $8 \mathrm{~h}$ ) in the same location of stomach which showed that the tablet has residence time of $8 \mathrm{~h}$. It may be due to the strong adhesive property of the gum that has been proved by in vitro mucoadhesive strength studies and physical evaluation of mucoadhesive tablets. Earlier reported by Mahesh et al that most of natural polymers contain two major polysaccharides fraction with equivalent weight about 700 and 4000 (Mahesh et al., 2006). On hydrolysis they yield mostly D-xylose L-arabinose and aldobiouronic acid. In contact with aqueous medium, the mucilage swell and thus could be responsible for bioadhesion by simple physical or hydrogen bonding with the mucus components. Hence, the bioadhesive property of the tablet which prepared using MMZ and Guar Gum assisted them to stay in the upper part of gastro intestinal tract.

\section{CONCLUSION}

The polymers are playing an important role in field of controlled or sustained release drug delivery system. The selected natural mucilage from seed of Manilkara 
zapota was successfully tested against their adhesive characteristic in the available physical studies like shear stress measurement, wihelmy's method, detachment force measurement, recording of adherence, falling sphere method, rotating cylinder method, falling liquid film technique, ex-vivo residence time, in-vitro wash off test and in vivo mucoadhesive strength along with some synthetic polymer such as HPMCE5LV and Guar Gum. The results were comparable to that of same synthetic polymer. The in vivo study of plain isolated natural mucoadhesive agent (in tablet form) seeds of Manilkara zapota at albino rabbits also shows a good response in mucoadhesive characterization analysis. Further the result showed mucilage obtained from seeds of Manilkara zapota had mucoadhesive character and if any modifications are done in chemical structure then it may possess an enhanced adhesiveness, which may replaces the synthetic non-ideal mucoadhesive polymer.

\section{REFERENCE}

AGAIAH, B.G.; SWAMY, K.S.; PRAVEEN, K.V. Formulation and evaluation of bioadhesive buccal tablets of simvastatin. J. Adv. Pharm. Sci., v.1, n.1, p.29-38, 2011.

ASANA, G.S. Mucoadhesive gastro intestinal drug delivery system: an overview. Pharmainfo.net., v.5, n. 6, 2007.

BHARDWAJ, T.R.; KANWAR, M.; LAL, R.; GUPTA, A. Natural gums and modified natural gums as sustained release carriers. Drug Dev. Ind. Pharm., v.26, n.10, p.1025$1038,2000$.

BHAVIN, P.; PIYUSH, P.; BHOSALE, A.; HARDIKAR, S.; MUTHA, S.; GANESH, C. Evaluation of tamarind seed polysaccharide as a mucoadhesive and sustained release component of nifedipine buccoadhesive tablet and comparison with HPMC and sodium CMC. Int. J. Pharmtech. Res., v.1, n.3, p.404-410, 2009.

DESHMUKH, V.N.; JADHAV, J.K.; SAKARKAR, D.M. Formulation and in vitro evaluation Theophylline anhydrous bioadhesive. Asian J. Pharm., v.3, n.1, p.54-58, 2009.

JANI, G.K.; SHAH, D.P. Evaluation of mucilage of Hibiscus rosasinensis Linn as rate controlling matrix for sustained release of diclofenac. Drug. Dev. Ind. Pharm., v.34, n.8, p.807-816, 2008.
KOKATE C.K.; PUROHIT A.P.; GOKHALE S.B. Pharmacognosy. 30.ed. Nirali Prakashan: Pune, 2005. p.211-212.

KULKARNI G.T.; GOWTHAMARAJAN K.; RAO, B.G.; SURESH, B. Evaluation of binding properties of Plantago ovata and Trigonella foenum graecum mucilages. Indian drugs, v.39, n.8, p.422-425, 2002.

LEUNG, S.H.S.; ROBINSON, J.R. Polymer structure features contributing to mucoadhesion II. J. Control. Release, v.12, n.3, p.187-194, 1990.

MAHESH, D.C.; JAIN, P. CHAUDHARI, S.; RAJESH, S.; VAVIA, P.R. Novel sustained release, swellable and bioadhesive gastro retentive drug delivery system for Ofloxacin. Int. J. Pharm., v.316, n.1-2, p.86-92, 2006.

NAFEE, N.A.; ISMAIL, F.A.; BORAIE, N.A.; MORTADA, L.M. Mucoadhesive buccal patches of micronazole nitrate in-vitro/in-vivo performance and side effect of ageing. Int. J. Pharm., v.264, n.1-2, p.1-14, 2003.

PEH, K.K.; WONG, C.F. Polymeric Films as vehicle for buccal drug delivery: Swelling, mechanical and bioadhesive properties. J. Pharm. Pharm. Sci., v.2, n.2, p.53-61, 1999.

PRANSHU, T.; MADHAV, S.N.V. Recent advances in oral mucoadhesive drug delivery systems: a review. Int. J. Pharm. Res. Dev., v.3, n.2, p.151-162, 2011.

RAO, R.K.V.; BURI, P. A novel in situ method to test polymers and coated micro particles for bioadhesion. Int. J. Pharm., v.52, n.3, p.265-270, 1989.

RAO, Y.M.; VANI, G.; BALA, R.; CHAR, R. Design and evaluation of mucoadhesive drug delivery system. Drug. Dev. Ind. Pharm., v.35, p.558-565, 1998.

SENTHIL, V.; GOPALAKRISHNAN, S.; SURESH, K.R.; JAWAHAR, N.; GANESH, G.N.K.; NAGASAMY, VENKATESH. D. Mucoadhesive slow release tablet of theophylline: Design and evaluation. Asian J. Pharm., v.4, n. 1, p.64-68, 2010 .

SHINDE, G.V.; SUDHARSHINI, S.; STEPHENRATHINARAJ, B.; RAJVEER, H.C.; KUMARASWAMY, D.; GANESH, S.B. Formulation and evaluation of mucoadhesive tablets of niacin using different bioadhesive polymers. Int. J. Pharm. Biol. Sci., v.1, n.2, p.1-14, 2010. 
SMART, J.D.; KELLAWAY, L.W.; WORTHINGTON, H.E.C. An in-vitro investigation of mucosa-adhesive material for use of in controlled drug delivery. J. Pharm. Pharmacol., v.36, n.5, p.295-299, 1984.

TREASE G.E.; EVANS M.C. Textbook of pharmacognosy. 15.ed. London: Balliere, Tindall, 2002. p.188-192
VJERA, G.; DAVIDE, G.; ANDREAS, B.S. Comparison of the mucoadhesive properties of various polymers. Adv. Drug Deliver. Rev., v.57, n.11, p.1713-1723, 2005.

Received for publication on $26^{\text {th }}$ December 2013 Accepted for publication on $25^{\text {th }}$ February 2015 